\title{
SECRETAGOGOS DE INSULINA: RISCOS CARDIOVASCULARES E HIPOGLICÊMICOS
}

INSULIN SECRETAGOGUES: CARDIOVASCULAR AND HYPOGLYCEMIC RISK

SECRETAGOGOS DE INSULINA: RIESGO CARDIOVASCULAR Y HIPOGLUCÉMICO

André de Oliveira Baldoni, Nathália Vital Guilarducci, Adriana Cristina

Soares e Marcelo Gonzaga Freitas Araújo

Universidade Federal de São João Del-Rei (UFSJ) - Campus Centro-Oeste Dona Lindu (CCO)

Rua Sebastião Gonçalves Coelho, 400, Bairro Chanadour, CEP 35.501-296, Divinópolis - MG

Email: andrebaldoni@ufsj.edu.br

Submetido em 28/09/2014, Aceito em 25/11/2014

RESUMO: Frente ao aumento progressivo da prevalência de Diabetes Mellitus tipo 2 na população brasileira e da elevada prevalência de pacientes que utilizam glibenclamida para tratamento dessa morbidade, esta comunicação breve possui como objetivo principal apresentar os riscos cardiovasculares e hipoglicêmicos associados ao uso da glibenclamida e chamar a atenção das Comissões de Farmácia e Terapêutica (CFT) dos municípios brasileiros para que avaliem a relação risco/benefício para padronização de outra sulfoniluréia, visto que grande parte das Relações Municipais de Medicamentos Essenciais (REMUME) possuem apenas a glibenclamida como opção terapêutica de secretagogo de insulina.

PALAVRAS-CHAVE: Diabetes Mellitus; Glibenclamida; Medicamentos Essenciais. 
BALDONI, A.O., GUILARDUCCI, N.V., SOARES, A.C., ARAÚJO, M.G.F.

REF-ISSN1808-0804 Vol.XI (4),01-05, 2014.

ABSTRACT: Considering the progressive increase in the prevalence of type 2 diabetes in Brazilian population and the high prevalence of patients that use glibenclamide for the treatment of this disease, this brief communication aimed to present the cardiovascular and hypoglycemic risks associated with the glibenclamide use and draw attention of the Pharmacy and Therapeutics Committees (CFT) of Brazilian municipalities to assess the risk / benefit ratio for selection of another sulfonylurea, since the most of Municipal List of Essential Medicines (REMUME) have only glibenclamide as a therapeutic option of secretagogues insulin.

KEYWORDS: Diabetes Mellitus; Glyburide; Drugs, Essential.

RESUMÉN: Considerando el aumento progresivo de la prevalencia del diabetes tipo 2 en la población brasileña y la alta prevalencia de pacientes que utilizan glibenclamida para el tratamiento de esta enfermedad, esta breve comunicación tiene como principal objetivo presentar los riesgos asociados al sistema cardiovascular y de hipoglucemia con el uso de glibenclamida y alertar los Comités de Farmácia y Terapéutica (CFT) de los municípios brasileños para que evalúen la relación riesgo/beneficio para proceder la padronización de otra sulfonilurea, ya que la mayoría de las Relaciones Municipales de Medicamentos Esenciales (REMUME) tienen sólo glibenclamida como opción terapéutica entre los secretagogos de insulina.

PALABRAS CLAVE: Diabetes Mellitus; Gliburida; Medicamentos Esenciales.

\section{COMUNICAÇÃO BREVE:}

$\mathrm{Na}$ atualidade, observa-se aumento progressivo na quantidade de pessoas com diagnóstico de Diabetes Mellitus tipo 2 (DM2), e muitos destes indivíduos apresentam como morbidade associada os problemas cardiovasculares, sendo, inclusive, um das causas de morte nesses pacientes ${ }^{(1)}$. Dentre as classes de antidiabéticos orais mais utilizadas por estes pacientes estão as biguanidas (metformina) e as 


\section{- Revista Eletrônica de Farmácia}

BALDONI, A.O., GUILARDUCCI, N.V., SOARES, A.C., ARAÚJO, M.G.F.

REF-ISSN1808-0804 Vol.XI (4),01-05, 2014.

sulfoniluréias (glibenclamida,

secretagogos de insulina. O uso dos

glimepirida, gliclazida), sobretudo no secretagogos de insulina tem se âmbito do Sistema Único de Saúde mostrado efetivo na redução dos $(\mathrm{SUS})^{(2)}$. As sulfoniluréias são níveis de glicemia de jejum e de fármacos que reduzem glicemia hemoglobina glicada (HbA1c), no sanguínea pela estimulação da entanto, estudos recentes apontam liberação de insulina pelas células que o uso de algumas sulfoniluréias beta do pâncreas, por isso são, pode estar relacionado com maior também, denominados fármacos ocorrência

de problemas cardiovasculares ${ }^{(3-5)}$. Diante disso, é importante considerar que:

- O principal alvo dessa classe farmacológica é o receptor de sulfoniluréia (SUR), que está localizado no canal de potássio sensível a Adenosina trifosfato ( $\left.\mathrm{K}_{\mathrm{ATP}}\right)$. A inibição deste canal de $\mathrm{K}_{\mathrm{ATP}}$, nas células beta pancreáticas, pela ligação das sulfoniluréias ao seu receptor do tipo SUR1, leva à despolarização da membrana celular e facilita o influxo de cálcio para o interior da célula, que por sua vez promove a exocitose dos grânulos de insulina ${ }^{(6)}$.

- Porém além do subtipo SUR1, localizado no pâncreas, existem dois outros subtipos de receptores SUR, sendo o SUR2A e o SUR2B. O subtipo SUR2A está localizado no musculo cardíaco e quando ativado pode levar a perda do pré-condicionamento isquêmico do miocárdio, e o subtipo SUR2B presente no músculo liso vascular quando ativado impede o relaxamento vascular, ambos os efeitos se dão pelo fechamento do canal de $\mathrm{K}_{\text {ATP }}$ induzido pelas sulfoniluréias ${ }^{(6)}$.

- A glibenclamida, que é uma das sulfonilurérias mais utilizadas no Brasil, atua nos receptores do pâncreas (SUR1) para exercer o efeito farmacológico, mas também atua nos receptores SUR2A (miocárdio) e SUR2B (músculo liso vascular) ${ }^{(7)}$. Segundo Brown (2012) esta falta de seletividade pelos receptores SUR da glibenclamida pode ocasionar eventos adversos cardiovasculares que podem comprometer a segurança da farmacoterapia do paciente ${ }^{(8)}$. 


\section{- Revista Eletrônica de Farmácia}

BALDONI, A.O., GUILARDUCCI, N.V., SOARES, A.C., ARAÚJO, M.G.F.

REF-ISSN1808-0804 Vol.XI (4),01-05, 2014.

Frente a estas evidências é importante destacar que as sulfonulurérias gliclazida e glimepirida atuam seletivamente no receptor SUR1, o que nos direciona a categorizá-las como opções terapêuticas mais seguras, sobretudo em pacientes com histórico de doenças cardiovasculares ${ }^{(3)}$. Diante disso, sugere-se que os profissionais que atuam na prática clínica levem em consideração estes riscos no momento da individualização da terapêutica.

Além disso, é importante destacar que a glibenclamida possui maior risco de causar crises hipoglicêmicas, sobretudo em pacientes idosos. Esse risco de hipoglicemia aumentando é característico das sulfoniluréias de ação longa ${ }^{(9)}$.

\section{REFERÊNCIAS}

1. ADA - American Diabetes Association. Diabetes facts and figures. 2014, Nov, 18. Disponível: http://www.diabetes.org/diabetes-statistics.jsp.

2. Guidoni CM, Borges APS, FREITAS O, PEREIRA LRL. Prescription patterns for diabetes mellitus and therapeutic implications: a population-based analysis. Arq Bras Endocrinol Metab. 2012; 56 (2): 120-127.

3. Matos MC, Branchtein L. O uso de antidiabéticos orais no paciente com diabetes mellitus e doença cardíaca. Revista da sociedade de cardiologia do RS. 2006; ano XV (8): 1-4. riscos cardiovasculares e hipoglicêmicos associados ao rápido processo de envelhecimento populacional brasileiro, nos atenta para a necessidade de padronização e seleção de opções terapêuticas mais seguras para os idosos, de forma a evitar complicações relacionadas ao uso destes medicamentos. Dessa forma, torna-se necessário que as Comissões de Farmácia e Terapêutica (CFT) dos municípios brasileiros avaliem a viabilidade de padronização de outra sulfoniluréia, visto que grande parte das Relações Municipais dos Medicamentos Essenciais (REMUME) dos municípios brasileiros possuem apenas a glibenclamida como opção terapêutica de secretagogos de insulina. 


\section{i) Revista Eletrônica}

BALDONI, A.O., GUILARDUCCI, N.V., SOARES, A.C., ARAÚJO, M.G.F.

REF-ISSN1808-0804 Vol.XI (4),01-05, 2014.

4. Schramm TK, Gislason GH, Vaag A, Rasmussen JN, Folke F, Hansen ML, et al. Mortality and cardiovascular risk associated with different insulin secretagogues compared with metformin in type 2 diabetes, with or without a previous myocardial infarction: a nationwide study. Eur Heart J. 2011; 32: 1900-1908.

5. Hung YC, Lin CC, Wang TY, Chang MP, Sung FC, Chen CC. Oral hypoglycaemic agents and the development of non-fatal cardiovascular events in patients with type 2 diabetes mellitus. Diabetes Metab Res Ver. 2013; 29: 673-679.

6. Contreras F, Romero B, Suárez N, González M, Fouillioux C, Guevara E, et al. Receptores Sur y Sulfonilureas en el tratamiento de la Diabetes Mellitus Tipo 2. AVFT. 2002; 21(2): 148- 155.

7. Abdelmoneim AS, Hasenbank SE, Seubert JM, Brocks DR, Light PE, Simpson $\underline{\mathrm{SH}}$. Variations in tissue selectivity amongst insulin secretagogues: a systematic review. Diabetes Obes Metab. 2012; 14 (2); 130-138.

8. Brown NJ. Cardiovascular effects of antidiabetic agents: focus on blood pressure effects of incretin-based therapies. J Am Soc Hypertens. 2012; 6(3): 163-168.

9. Wannmacher, L. Antidiabéticos orais: comparação entre diferentes intervenções. Uso racional de medicamentos: temas selecionados, ISSN 1810-0791. 2005; 2 (11). 